\section{Editorial}

Check for updates

\title{
Opportunistic salpingectomy in the Netherlands
}

\author{
Karl Tamussino \\ Department of Obstetrics and Gynecology, Medical University of Graz, Graz, Austria \\ - See the article "Factors influencing decision-making around opportunistic salpingectomy: \\ a nationwide survey" in volume 30 , e2.
}

Prevention is a central aspect of gynecologic care. Gynecologists routinely address prevention of cervical cancer, breast cancer, unwanted pregnancy and other issues. Proactive and prophylactic interventions are more common in gynecologic care than in many if not all medical specialties. Prevention is a big part of what we do.

In many countries screening programs have dramatically reduced death rates due to cervical cancer, leaving ovarian cancer as the main cause of gynecologic cancer death. Unfortunately, screening programs have not been shown to reduce mortality due to ovarian cancer. In Austria 3 times as many women now die ovarian cancer than of cervical cancer. In gynecologic oncology, ovarian cancer is our biggest unsolved problem.

Gynecologic Oncology, Korean Society of Gynecologic Oncology

This is an Open Access article distributed under the terms of the Creative Commons Attribution Non-Commercial License (https:// creativecommons.org/licenses/by-nc/4.0/) which permits unrestricted non-commercial use, distribution, and reproduction in any medium, provided the original work is properly cited.

ORCID IDs

Karl Tamussino (iD)

https://orcid.org/0000-0001-5016-4669

Conflict of Interest

No potential conflict of interest relevant to this article was reported.
The histologic origins of ovarian cancer were long obscure (another difference to cervical cancer, whose histologic development has been studied intensively for decades). Then, in the mid-1990s, the genetic alterations underlying high rates of ovarian and breast cancer in certain families were identified as mutations of the BRCA genes on chromosomes 13 and 17. Soon the technology was developed to test women at high familial risk, and women who tested positive for $B R C A$ mutations were offered prophylactic bilateral salpingooophorectomy. In the Netherlands, pathologists receiving these specimens from women at high risk studied them intensively and in 2001 Piek et al. [1] described so-called dysplasias in the tubal fimbria. Intensive subsequent studies established these dysplasias - now called serous tubal intraepithelial carcinomas or STICs - as the origin of many if not all serous pelvic cancers [2].

But does it follow that removing tubes reduces the risk of ovarian cancer? Epidemiologic data from Sweden and Denmark suggest that it does. A nationwide population-based study of more than 5 million women in Sweden identified a hazard ratio of 0.35 (95\% confidence interval $=0.17-0.73$ ) in women after bilateral salpingectomy compared with unexposed controls [3]. A nationwide registry-based study in Denmark reported that bilateral salpingectomy reduced epithelial ovarian cancer risk by $42 \%$ [4]. However, association does not prove causation. 
The strong evidence for the tubal origin of serous cancers and the epidemiologic data suggesting risk reduction led professional societies in a number of countries, beginning with Canada [5], to recommend prophylactic bilateral salpingectomy (PBS; also called opportunistic salpingectomy, OS), at the time of gynecologic surgery or cesarean section in appropriate women [6]. These societies concluded that the potential risks outweighed the potential risks of OS (PBS). However, we have no prospective data.

In this issue of Journal of Gynecologic Oncology, Steenbeek et al. [7] explored factors influencing decision making around OS in the Netherlands, a country where there are no official recommendations regarding PBS (OS). A total of 969 surgical gynecologists and trainees were surveyed and about $51 \%$ responded. As the authors acknowledge, this modest response rate is a possible source of bias, as colleagues with little interest in PBS (OS) might be less inclined to complete the 44-item survey. The results were "diverse" and reflect a lack of consensus in the Netherlands, but most respondents discussed and performed PBS (OS) at the time of benign hysterectomy. Colleagues were a bit more reserved about PBS (OS) at the time of vaginal hysterectomy. Importantly, cost was not an issue for patients as salpingectomy was covered by insurance.

It is a bit ironic that the Netherlands and Sweden, the countries that have provided the initial impetus and evidence for the concept of PBS (OS) to prevent ovarian cancer, do not have national recommendations for (or against) PBS (OS). In Sweden a randomized study looking at a range of outcomes of opportunistic salpingectomy has been initiated. The Hysterectomy and OPPortunistic Salpingectomy study (trial registry at ClinicalTrials.gov, NCT 03045965) will look at short-term complications, intermediate-term effects on ovarian function, and the risk of ovarian cancer over a follow-up of 10-30 years in women undergoing hysterectomy with or without salpingectomy. The long-term objectives will need 4,400 randomized patients, though eligible women can participate even if not willing to be randomized.

Until prospective evidence is available (and this will take decades) physicians in countries with official recommendations can rely on and follow these. In countries without official recommendations physicians should still discuss the issue of OS (PBS) before surgery in appropriate women, offer their best clinical judgement, and make a joint decision.

\section{REFERENCES}

1. Piek JMJ, van Diest PJ, Zweemer RP, Jansen JW, Poort-Keesom RJ, Menko FH, et al. Dysplastic changes in prophylactically removed Fallopian tubes of women predisposed to developing ovarian cancer. J Pathol 2001;195:451-6.

PUBMED | CROSSREF

2. Labidi-Galy SI, Papp E, Hallberg D, Niknafs N, Adleff V, Noe M, et al. High grade serous ovarian carcinomas originate in the fallopian tube. Nature Commun 2017;8:1093. PUBMED | CROSSREF

3. Falconer H, Yin L, Grönberg H, Altman D. Ovarian cancer risk after salpingectomy: a nationwide population-based study. J Natl Cancer Inst 2015;107:dju410. PUBMED | CROSSREF

4. Madsen C, Baandrup L, Dehlendorff C, Kjaer SK. Tubal ligation and salpingectomy and the risk of epithelial ovarian cancer and borderline ovarian tumors: a nationwide case-control study. Acta Obstet Gynecol Scand 2015;94:86-94.

PUBMED | CROSSREF 
5. McAlpine JN, Hanley GE, Woo MM, Tone AA, Rozenberg N, Swenerton KD, et al. Opportunistic salpingectomy: uptake, risks, and complications of a regional initiative for ovarian cancer prevention. Am J Obstet Gynecol 2014;210:471.e1-11.

PUBMED | CROSSREF

6. Ntoumanoglou-Schuiki A, Tomasch G, Laky R, Taumberger N, Bjelic-Radisic V, Tamussino K. Opportunistic prophylactic salpingectomy for prevention of ovarian cancer: what do national societies advise? Eur J Obstet Gynecol Reprod Biol 2018;225:110-2. PUBMED | CROSSREF

7. Steenbeek MP, van Lieshout LA, Aarts JW, Piek JM, Coppus SF, Massuger LF, et al. Factors influencing decision-making around opportunistic salpingectomy: a nationwide survey. J Gynecol Oncol 2019;30:e2. CROSSREF 